CLINICAL STUDY

\title{
Fibroblast cholesterol efflux to plasma from metabolic syndrome subjects is not defective despite low high-density lipoprotein cholesterol
}

\author{
Robin P F Dullaart ${ }^{1}$, Albert K Groen ${ }^{2}$, Geesje M Dallinga-Thie ${ }^{3}$, Rindert de Vries ${ }^{1}$, Wim J Sluiter ${ }^{1}$ and Arie van Tol ${ }^{1,4}$ \\ ${ }^{1}$ Department of Endocrinology, University of Groningen and University Medical Center Groningen, PO Box 30001, 9700 RB Groningen, The Netherlands, \\ Departments of ${ }^{2}$ Laboratory of Biochemistry, ${ }^{3}$ Laboratory of Experimental Vascular Medicine, Academic Medical Center Amsterdam, The Netherlands and \\ ${ }^{4}$ Departments of Cell Biology and Genetics, Erasmus University Medical Center, Rotterdam, The Netherlands \\ (Correspondence should be addressed to R P F Dullaart; Email: r.p.f.dullaart@int.umcg.nl)
}

\begin{abstract}
Objective: We tested whether in metabolic syndrome (MetS) subjects the ability of plasma to stimulate cellular cholesterol efflux, an early step in the anti-atherogenic reverse cholesterol transport pathway, is maintained despite low high-density lipoprotein (HDL) cholesterol.

Design: In 76 subjects with and 94 subjects without MetS based on the National Cholesterol Education Program Adult Treatment Panel III (NCEP ATP III) criteria, we determined plasma (apo)lipoproteins, pre- $\beta$-HDL formation, phospholipid transfer protein (PLTP) activity, cholesterol esterification (EST), cholesteryl ester transfer (CET), adiponectin, and the ability of plasma from each subject to stimulate cholesterol efflux out of cultured fibroblasts obtained from a single donor.

Results: Apo E, PLTP activity, EST, and CET were higher $(P=0.04$ to $<0.001)$, whereas adiponectin was lower in MetS subjects $(P<0.01)$. Pre- $\beta$-HDL and pre- $\beta$-HDL formation were not different between subjects with and without MetS. Cellular cholesterol efflux to plasma from MetS subjects was slightly higher versus plasma from subjects without MetS $(8.8 \pm 1.0$ vs $8.5 \pm 0.9 \%, P=0.05)$, but the difference was not significant after age, sex, and diabetes adjustment. Cellular cholesterol efflux was positively related to pre- $\beta$-HDL formation, EST, PLTP activity, and apo E $(P<0.05$ for all by multiple linear regression analysis), without an independent association with MetS and diabetes status.

Conclusions: The ability of plasma from MetS subjects to promote fibroblast cholesterol efflux is not defective, although HDL cholesterol is decreased. Higher cholesterol esterification, PLTP activity, and apo E levels may contribute to the maintenance of cholesterol efflux in MetS.
\end{abstract}

European Journal of Endocrinology 158 53-60

\section{Introduction}

The metabolic syndrome (MetS) represents a cluster of cardiovascular risk factors, including (central) obesity, high blood pressure, high plasma triglycerides, low highdensity lipoprotein (HDL) cholesterol, and hyperglycemia (1). In recent years, several expert groups have proposed (and revised) their criteria for MetS (2-5) with the National Cholesterol Education Program (NCEP) Expert Panel on Detection, Evaluation, and Treatment of High Blood Cholesterol in Adults (ATP III) criteria, originally appeared in 2001 (3) and being widely used in the literature. The existence of such a syndrome has been criticized, and it has been disputed whether resistance to insulin-stimulated glucose uptake should be regarded as the unifying pathophysiological abnormality (1). Nonetheless, a systemic review has shown that cardiovascular risk is increased by $65 \%$ in subjects fulfilling the NCEPATP III criteria for MetS (6), an observation that was recently extended by the DECODE study group (7).
The reverse cholesterol transport (RCT) process directs cholesterol via HDL from the peripheral tissues to the liver for subsequent excretion in the bile, and is considered to represent a pathway that protects against atherosclerosis development (8-10). Efflux of cholesterol from peripheral cells to extracellular acceptors is an important early step in $\mathrm{RCT}(11,12)$. Cellular cholesterol removal is governed by several still incompletely understood mechanisms, including aqueous diffusion, transport of cholesterol via the ATP-binding cassette $(\mathrm{ABC})$ transporters, $\mathrm{ABCA} 1$, and ABCG1, as well as via scavenger receptor class $B$ type 1 (SR-BI) (11-14). Small, lipid-poor, or lipid-free apo A-Icontaining particles, commonly designated pre- $\beta-\mathrm{HDL}$, are considered to be the initial acceptors of cell-derived cholesterol via the ABCA1 transporter $(8,10,15,16)$. Among other factors, the metabolism of these particles is governed in a complex way by phospholipid transfer protein (PLTP) and cholesteryl ester transfer protein (CETP), which contribute to pre- $\beta$-HDL generation, and by lecithin:cholesterol acyltransferase (LCAT), which 
decreases pre- $\beta$-HDL $(8,10,16,17)$. SR-BI and the recently discovered ABCG1 transporter are able to mediate cholesterol efflux to mature $\alpha$-HDL particles $(13,14)$.

In MetS, increased catabolism of HDL particles contributes to low plasma levels of its major apolipoproteins (apos), apo A-I and A-II, and a drop in lipoprotein A-I:A-II, i.e., HDL particles that contain both apos $(18,19)$, but little is known about possible abnormalities in the RCT pathway. One study in MetS subjects has demonstrated a normal potential of individual skin fibroblasts, a cell system that expresses ABCA1 but hardly any SR-BI $(11,12,20,21)$, to transport cholesterol to purified apo A-I, acting as a cholesterol acceptor (22). On the other hand, cholesterol efflux from monocyte-derived macrophages to apo A-I is defective in a considerable number of subjects with isolated low HDL cholesterol, even in the absence of mutations in ABCA1 (23). Using Fu5AH cells, which express SR-BI but no $\operatorname{ABCA} 1(11,12)$, cholesterol efflux to serum or plasma is maintained in hypertriglyceridemic (24) and insulinresistant subjects (25).

We questioned whether plasma from MetS subjects maintains the ability to promote cholesterol efflux out of cultured human fibroblasts despite its low HDL concentration. In the present study, we compared the ability of plasma to promote cellular cholesterol removal, as well as plasma pre- $\beta$-HDL, PLTP activity, CET, and cholesterol esterification (EST) between subjects with MetS and without MetS.

\section{Subjects and methods}

The study was approved by the medical ethics committee of the University Medical Center Groningen, the Netherlands. Participants were recruited by advertisement in local newspapers, and written informed consent was obtained from all of them. All participants were aged $>18$ years. Smoking, use of lipid-lowering drugs, clinically manifest cardiovascular disease, renal disease (elevated serum creatinine or urinary albumin $>20 \mathrm{mg} / \mathrm{l}$ ), thyroid disease (abnormal serum thyrotrophin level, or use of thyroxine or antithyroid drugs), and alcohol use $>3$ beverages per day were the exclusion criteria. Diabetic patients were included, except when using insulin or thiazolidinediones. The use of antihypertensive medication was allowed.

MetS was defined according to the NCEP ATP III 2001 criteria (3). Three or more of the following criteria were required for categorization of subjects with MetS: waist circumference $>102 \mathrm{~cm}$ for men and $>88 \mathrm{~cm}$ for women; plasma triglycerides $\geq 1.7 \mathrm{mmol} / \mathrm{l}$; HDL cholesterol $<1.0 \mathrm{mmol} / \mathrm{l}$ for men and $<1.3 \mathrm{mmol} / \mathrm{l}$ for women; hypertension (blood pressure $\geq 130 / 85 \mathrm{mmHg}$ or use of antihypertensive medication); fasting glucose $\geq 6.1 \mathrm{mmol} / \mathrm{l}$; or known diabetes. Type 2 diabetes mellitus had been previously diagnosed by primary care physicians using blood glucose cut-off values as defined by the WHO (2), and patients were treated with either diet alone or in combination with oral glucose-lowering agents.
All participants were evaluated after an overnight fast. BMI was calculated as weight $(\mathrm{kg})$ divided by height $(\mathrm{m})$ squared. Waist circumference was measured on bare skin between the tenth rib and the iliac crest. Blood pressure was measured after a 15-min rest at the left arm in the sitting position using a sphygmomanometer. Homeostasis model assessment was used as a measure of insulin sensitivity $\left(\mathrm{HOMA}_{\mathrm{ir}}\right)$ using the equation: fasting plasma insulin $(\mathrm{mU} / \mathrm{l}) \times$ glucose $(\mathrm{mmol} / \mathrm{l}) / 22.5(26)$.

\section{Laboratory measurements}

After blood collection, EDTA-containing plasma samples were prepared at $4{ }^{\circ} \mathrm{C}$. The samples were directly stored at $-80^{\circ} \mathrm{C}$ until shortly before the various analyses, except for plasma glucose and glycated hemoglobin $\left(\mathrm{HbA}_{1 \mathrm{c}}\right)$, which were measured directly after blood collection.

Plasma cholesterol and triglycerides were assayed by routine enzymatic methods (Roche/Hitachi catalogue numbers 11876023 and 11875540 respectively; Roche Diagnostics $\mathrm{GmbH})$. HDL cholesterol was determined with a homogeneous enzymatic colorimetric test (Roche/Hitachi cat. no. 03030024), and its measurement is unchanged after a prolonged period of storage at $-80^{\circ} \mathrm{C}$. Non-HDL cholesterol was calculated as the difference between plasma total cholesterol and HDL cholesterol. Apolipoproteins (apos) A-I and B were assayed by immunoturbidimetry (Roche/Cobas Integra Tinaquant cat. no. 03032566 and 033032574 respectively; Roche Diagnostics). Apo E was measured using an immunoturbidimetric assay (cat. no. 417-35906; Wako Inc., Osaka, Japan).

Plasma pre- $\beta$-HDL concentration was measured by crossed immunoelectrophoresis, essentially as described elsewhere (27), except that anti-human apo A-I was used. Briefly, plasma samples were thawed while kept on ice, and $0.9 \mu \mathrm{mol} / \mathrm{l}$ Pefabloc SC (Boehringer-Roche) and $1.8 \mu \mathrm{g} / \mathrm{l} \mathrm{Trasylol}$ (Bayer) were added to inhibit proteolysis (both final concentrations). The crossed immunoelectrophoresis consisted of agarose electrophoresis in the first dimension for the separation of lipoproteins with pre- $\beta$ and $\alpha$-mobility. Antigen migration from the first agarose gel into the second agarose gel, containing goat antihuman apo A-I antiserum $(0.66 \% \mathrm{vol} / \mathrm{vol}$; Midland Bioproducts Corporation, Boone, IA, USA, cat. no. 71101), was used to quantitatively precipitate apo A-I. The antiserum was monospecific for human apo A-I using an immunodiffusion assay. Lipoprotein electrophoresis was carried out in 1\% (weight/vol) agarose gels in Tris $(80 \mathrm{mmol} / \mathrm{l})$-Tricine $(24 \mathrm{mmol} / \mathrm{l})$ buffer, $5 \%$ ( vol/vol) polyethylene glycol $300(\mathrm{pH} \mathrm{8.6)}$, and run in an LKB 2117 system $\left(4^{\circ} \mathrm{C}\right.$ for $\left.3 \mathrm{~h}, 210 \mathrm{~V}\right)$. Plasma was applied at $3 \mu \mathrm{l} /$ well. The track of the first agarose gel was excised and annealed with melted agarose to a gel containing $0.66 \%(\mathrm{vol} / \mathrm{vol})$ goat anti-human apo A-I anti-serum (Midland Bioproducts corporation) and $0.01 \% \mathrm{~m} / \mathrm{V}$ Tween 20 , which was cast on GelBond film 
(Amersham). The plate was run in an LKB 2117 system $\left(4{ }^{\circ} \mathrm{C}\right.$ for $\left.20 \mathrm{~h}, 50 \mathrm{~V}\right)$ in Tris-Tricine buffer. The unreacted antibody was removed by extensive washing with saline. The gel was stained with Coomassie Brilliant Blue R-250 and subsequently dried. The gels were scanned with an HP Scanjet 5470c. Areas under the pre- $\beta$-HDL and $\alpha-\mathrm{HDL}$ peaks were calculated using the free UTHSCSA ImageTool program (developed at the University of Texas Health Science Center at San Antonio, Texas, and available on the Internet from an anonymous FTP: ftp://maxrad6. uthscsa.edu). The pre- $\beta$-HDL area was expressed as the percentage of the sum of apo A-I in the pre- $\beta$-HDL and the $\alpha$-HDL areas. Pre- $\beta$-HDL formation, i.e., the ability of plasma to generate pre- $\beta$-HDL, was assessed using the same procedure, but after 24-h incubation of plasma at $37^{\circ} \mathrm{C}$ under conditions of LCAT inhibition. To this end, iodoacetate (final concentration $1.0 \mathrm{mmol} / \mathrm{l}$ ) was added directly after thawing the samples. Pre- $\beta-\mathrm{HDL}$ and pre- $\beta$ HDL formation were calculated using the total plasma apo A-I concentration and were expressed in apo A-I.

Plasma PLTP activity was assayed with a phospholipid vesicles-HDL system, using $\left[{ }^{14} \mathrm{C}\right]$-labeled dipalmitoyl phosphatidylcholine (28). This method is specific for the PLTP activity, and the PLT promoting property of CETP does not interfere with the assay. Plasma PLTP activity is related to the activity in human reference pool plasma and is expressed in arbitrary units (AU; $100 \mathrm{AU}$ corresponds to $13.6 \mu \mathrm{mol}$ phosphatidylcholine transferred, $\mathrm{ml} / \mathrm{h}$ ). Plasma CET was determined as described previously (29). Briefly, $\left[{ }^{3} \mathrm{H}\right]$ cholesterol was equilibrated for $24 \mathrm{~h}$ at $4{ }^{\circ} \mathrm{C}$ with plasma cholesterol followed by incubation of plasma at $37^{\circ} \mathrm{C}$. Thereafter, apo B-containing lipoproteins were precipitated and the labeled cholesteryl esters were separated from the labeled unesterified cholesterol on silica columns. Plasma EST was measured as the formation of cholesteryl esters after the addition of $\left[{ }^{3} \mathrm{H}\right]$ cholesterol to plasma as described (29). Equilibration of added $\left[{ }^{3} \mathrm{H}\right]$ cholesterol was obtained after incubation at $4{ }^{\circ} \mathrm{C}$ for $24 \mathrm{~h}$. Subsequently, the plasma was incubated at $37^{\circ} \mathrm{C}$.

Cholesterol efflux to plasma was determined using human fibroblasts as cholesterol donor, essentially as described $(20,30)$. In brief, fibroblasts were obtained from a normolipidemic control and were cultured (until passages 5-15) in 24-well culture plates to full confluency. The cells were cultured in Dulbecco's Modified Eagle's Medium (DMEM) supplemented with $10 \% \mathrm{vol} / \mathrm{vol}$ fetal calf serum (FCS). After washing them with DMEM, they were loaded with $\left[{ }^{3} \mathrm{H}\right]$ cholesterol $(0.5 \mu \mathrm{Ci} / \mathrm{ml})$ during $24 \mathrm{~h}$ in the presence of added unlabelled cholesterol $(30 \mu \mathrm{g} / \mathrm{ml})$, thereby inducing ABCA1 (20). After cholesterol loading, cells were washed three times with $0.2 \% \mathrm{PBS} / \mathrm{BSA}$ (weight/vol). The efflux assay was started by the addition of the individual plasma sample, diluted to $1 \%$ in efflux medium. Heparin $(1.25 \mathrm{U} / \mathrm{ml})$ was added to prevent clotting. After 4 -h incubation at $37^{\circ} \mathrm{C}$, the medium was collected and centrifuged. $\left[{ }^{3} \mathrm{H}\right]$ cholesterol was quantified by liquid scintillation counting. Total cellular $\left[{ }^{3} \mathrm{H}\right]$ cholesterol was determined after extraction of the cells with 2-propanol. The percentage efflux was calculated by dividing the radioactive counts in the efflux medium by the sum of the counts in the medium and the cell extract. All plasma samples were analyzed in duplicate, and values were corrected for radioactivity appearing in the culture medium in the absence of plasma. To be able to normalize results between series of experiments and to correct for day-to-day variation, efflux to human plasma pool was determined in quadruplicate. Experiments with $\left[{ }^{14} \mathrm{C}\right]$ cholesterol were carried out, demonstrating that influx of $\left[{ }^{14} \mathrm{C}\right]$ cholesterol from the plasma to the cells was consistently $<10 \%$ (triplicate measurements using three different plasma samples). Therefore, the assumption is valid that efflux is almost exclusively from the cells to the medium under the current assay conditions. Moreover, the ability of plasma to stimulate cellular cholesterol efflux was unaffected by prolonged storage of the samples at $-80{ }^{\circ} \mathrm{C}$ (data not shown).

Plasma insulin was measured with a microparticle enzyme immunoassay (AxSYM insulin assay; Abbott Laboratories). Free fatty acids (FFAs) were assayed by a commercially available kit (Wako Chemicals, Neuss, Germany, cat. no. 999-75406). High-sensitive C reactive protein (CRP) was assayed by nephelometry with a threshold of $0.175 \mathrm{mg} / \mathrm{l}$ (BNII N; Dade Behring, Marburg, Germany). Plasma adiponectin was assayed using Luminex xMAP technology with a commercially available kit, according to the manufacturer's instructions (Linco Research Inc., St Charles, MO, USA; Lincoplex panel A cat. no. HADK1-61K-A, purchased from Nuclilab Inc. Ede, the Netherlands). Adiponectin, as measured with this technology, is strongly correlated $\left(r^{2}=0.95\right)$ with assay results obtained by enzymelinked immunoassays from Linco Inc. (data provided by the manufacturer). Glucose was measured with an APEC glucose analyzer (APEC Inc., Danvers, MA, USA) and $\mathrm{HbA}_{1 \mathrm{c}}$ by HPLC (Bio-Rad; reference ranges $4.6-6.1 \%)$.

\section{Statistical analysis}

Data are shown as mean \pm s.D. or in the case of a skewed distribution as geometric mean (95\% confidence intervals, CI). $\chi^{2}$ analysis was used to evaluate the differences in proportions among the groups. Betweengroup differences were evaluated by Student's $t$-tests or ANOVA where appropriate. When variables had a skewed distribution, logarithmically transformed values were used. Univariate correlations were assessed by linear regression analysis, using Pearson's correlation coefficients. Multiple linear regression analysis was used to reveal independent relationships between variables. Two-sided $P$ values $<0.05$ were considered to be statistically significant. 


\section{Results}

A total of 170 subjects (99 men, 71 women) were included in the study. Out of these, 76 subjects fulfilled the criteria for MetS, whereas 94 did not. Age and sex distribution were not significantly different between subjects with and without MetS (Table 1). Diabetes mellitus $(P<0.001)$ was found in 55 subjects with and 26 without MetS. Out of these diabetic subjects, 24 were treated with diet alone, 16 used biguanides alone, 17 used sulfonylurea alone, and 24 used both glucoselowering drugs. Twenty-eight of the MetS subjects and seven of the subjects without MetS used antihypertensive drugs $(P<0.001)$. The most frequently used medications were ACE inhibitors, $\beta$-blockers, diuretics, and angiotensin II antagonists, alone and in combination. Two women in each group used estrogens.

BMI, waist circumference, blood pressure, plasma glucose, insulin, $\mathrm{HOMA}_{\mathrm{in}}$ FFA, and CRP levels were higher in subjects with MetS compared with subjects without MetS, and these differences remained significant after adjustment for age, sex, and diabetes status (Table 1). Plasma adiponectin, HDL cholesterol, and apo A-I were decreased, whereas non-HDL cholesterol, triglycerides, apo B, and apo E levels were increased in MetS subjects (Table 1).

As shown in Table 2, PLTP activity, EST, and CET were higher in MetS subjects and remained so after age, sex, and diabetes status adjustment. Plasma pre- $\beta$-HDL and pre- $\beta$-HDL formation were similar in subjects with and without MetS. The ability of plasma to promote cholesterol efflux out of fibroblasts was slightly higher in subjects with MetS compared with subjects without MetS, but the difference in cholesterol efflux was not significant after controlling for age, sex, and diabetes. We also compared non-diabetic subjects with $(n=21)$ and without MetS $(n=68)$, diabetic subjects with MetS $(n=55)$, and diabetic subjects without MetS $(n=26$; Table 3). Pre- $\beta$-HDL and pre- $\beta$-HDL formation were similar in these four groups, whereas PLTP activity, EST, and CET were the highest in subjects with both MetS and diabetes. Cellular cholesterol efflux was somewhat higher in diabetic subjects with MetS compared with diabetic subjects without MetS, but was similar between non-diabetic subjects with and without MetS.

In univariate regression analysis, cellular cholesterol efflux to plasma was positively correlated with plasma apo E, pre- $\beta$-HDL formation, PLTP activity, EST, and CET in subjects with and without MetS, as well as in the combined subjects (Table 4). Cellular cholesterol efflux was not significantly correlated with HDL cholesterol, plasma apo A-I, and adiponectin in either group.

Multiple linear regression analysis was done to discern the independent relationships between HDL-related variables and cellular cholesterol efflux to plasma. In this analysis, only those HDL-related variables that were significantly correlated with cellular cholesterol efflux in univariate analysis were included. In the combined subjects, cellular cholesterol efflux to plasma was positively and significantly related to plasma pre- $\beta$-HDL formation, EST, PLTP activity, and apo E, independent of age $(P=0.86)$, sex $(P=0.71)$, the presence of MetS $(P=0.99)$, and diabetes status $(P=0.44$; Table 5$)$. Furthermore, the relationships shown in Table 5 remained significant, when the use of glucose-lowering drugs $(P=0.42)$ and antihypertensive medication $(P=0.46)$ was taken into account (data not shown).

Table 1 Clinical and biochemical characteristics in subjects with and without metabolic syndrome.

\begin{tabular}{|c|c|c|c|c|}
\hline & $\begin{array}{l}\text { Metabolic syndrome absent } \\
(n=94)\end{array}$ & $\begin{array}{l}\text { Metabolic syndrome present } \\
(n=76)\end{array}$ & $P$ value & $P^{\star}$ value \\
\hline $\operatorname{Sex}(m / f)$ & $57 / 37$ & $42 / 34$ & 0.58 & \\
\hline Age (years) & $56 \pm 10$ & $58 \pm 9$ & 0.07 & \\
\hline BMI $\left(\mathrm{kg} / \mathrm{m}^{2}\right)$ & $26.0 \pm 3.9$ & $28.6 \pm 4.8$ & $<0.001$ & $<0.001$ \\
\hline Waist $(\mathrm{cm})$ & $87 \pm 11$ & $104 \pm 12$ & $<0.001$ & $<0.001$ \\
\hline Systolic BP (mmHg) & $131 \pm 19$ & $145 \pm 18$ & $<0.001$ & 0.003 \\
\hline Diastolic BP (mmHg) & $81 \pm 10$ & $89 \pm 9$ & $<0.001$ & 0.003 \\
\hline Glucose $(\mathrm{mmol} / \mathrm{l})$ & $6.1 \pm 1.4$ & $8.4 \pm 2.6$ & $<0.001$ & 0.001 \\
\hline Insulin (mU/l) & $5.6(5.2-6.4)$ & $11.8(10.6-13.3)$ & $<0.001$ & $<0.001$ \\
\hline $\mathrm{HOMA}_{\mathrm{ir}}\left(\mathrm{mU} \times \mathrm{mmol} /\left(\mathrm{I}^{2} \times 22.5\right)\right)$ & $1.54(1.36-1.74)$ & $4.22(3.69-4.83)$ & $<0.001$ & 0.001 \\
\hline Adiponectin $(\mathrm{mg} / \mathrm{l})$ & $23.1(20.2-26.4)$ & $15.8(13.6-18.4)$ & $<0.001$ & $<0.001$ \\
\hline FFA $(\mathrm{mmol} / \mathrm{l})$ & $0.29 \pm 0.11$ & $0.36 \pm 0.12$ & $<0.001$ & 0.03 \\
\hline CRP (mg/l) & $1.10(0.87-1.39)$ & $2.27(1.84-2.78)$ & $<0.001$ & 0.001 \\
\hline Total cholesterol $(\mathrm{mmol} / \mathrm{l})$ & $5.58 \pm 0.99$ & $5.56 \pm 0.98$ & 0.90 & 0.39 \\
\hline Non-HDL cholesterol (mmol/l) & $4.03 \pm 1.08$ & $4.38 \pm 0.99$ & 0.03 & 0.004 \\
\hline HDL cholesterol $(\mathrm{mmol} / \mathrm{l})$ & $1.54 \pm 0.38$ & $1.18 \pm 0.33$ & $<0.001$ & $<0.001$ \\
\hline Triglycerides $(\mathrm{mmol} / \mathrm{l})$ & $1.08(1.03-1.13)$ & $1.35(1.29-1.41)$ & $<0.001$ & $<0.001$ \\
\hline Apo B $(\mathrm{g} / \mathrm{l})$ & $0.91 \pm 0.24$ & $1.00 \pm 0.22$ & 0.01 & 0.001 \\
\hline Apo A-I (g/l) & $1.45 \pm 0.20$ & $1.30 \pm 0.23$ & $<0.001$ & $<0.001$ \\
\hline Apo E (g/l) & $0.038 \pm 0.010$ & $0.042 \pm 0.012$ & 0.01 & 0.009 \\
\hline
\end{tabular}

Data are shown as mean \pm s.D. or geometric mean ( $95 \%$ confidence intervals). $\mathrm{HOMA}_{\mathrm{ir}}$, homeostasis model assessment (insulin sensitivity); FFA, free fatty acids; CRP, high-sensitive C-reactive protein; apo, apolipoprotein. * $P$ value, adjusted for age, sex, and diabetes status. 
Table 2 Plasma pre- $\beta$-high-density lipoprotein (HDL; formation), phospholipid transfer protein (PLTP) activity, cholesterol esterification (EST), cholesteryl ester transfer (CET), and cholesterol efflux from cultured fibroblasts to plasma from subjects without and with metabolic syndrome.

\begin{tabular}{|c|c|c|c|c|}
\hline & $\begin{array}{l}\text { Metabolic syndrome absent } \\
(n=94)\end{array}$ & $\begin{array}{l}\text { Metabolic syndrome present } \\
(n=76)\end{array}$ & $P$ value & $P^{\star}$ value \\
\hline Pre- $\beta$-HDL (apo A-I, g/l) & $0.052 \pm 0.020$ & $0.052 \pm 0.019$ & 0.90 & 0.68 \\
\hline Pre- $\beta$-HDL formation (apo A-I, g/l) & $0.312 \pm 0.069$ & $0.396 \pm 0.065$ & 0.13 & 0.24 \\
\hline PLTP activity (AU) & $94 \pm 10$ & $104 \pm 11$ & $<0.001$ & $<0.001$ \\
\hline EST $(\mathrm{nmol} / \mathrm{ml}$ per $\mathrm{h})$ & $56 . \overline{4} \pm 15.6$ & $63.8 \pm 17.0$ & $<0.001$ & $<0.001$ \\
\hline CET (nmol/ml per h) & $19.6+7.1$ & $25.4+8.3$ & $<0.001$ & $<0.001$ \\
\hline Cholesterol efflux (\%/4 h) & $8.5 \pm 0.9$ & $8.8 \pm 1.0$ & 0.05 & 0.08 \\
\hline
\end{tabular}

Data are shown as mean \pm s.D. or geometric mean ( $95 \%$ confidence intervals). ${ }^{\star} P$ value, adjusted for age, sex, and diabetes status.

\section{Discussion}

Our study shows that plasma apo B, apo E, EST, CET, as well as PLTP activity are increased, whereas plasma pre- $\beta$-HDL and pre- $\beta$-HDL formation are unaltered in the MetS subjects. Furthermore, using cultured human skin fibroblasts as cell system, we demonstrate for the first time that cholesterol efflux to plasma from the MetS subjects is maintained despite low HDL cholesterol. Essentially similar findings were obtained when comparing non-diabetic subjects with and without the MetS. In diabetic subjects, cholesterol efflux was slightly higher among those who fulfilled the criteria for the MetS. Cellular cholesterol efflux to plasma was found to be related to plasma EST, pre- $\beta$-HDL formation, PLTP activity, and apo E, without an independent association with the presence of the MetS and the diabetic state. Taken together, our data thus suggest that, as far as the ability of plasma to promote cholesterol efflux out of fibroblasts is concerned, this step in the RCT pathway is not impaired in the MetS.

Cholesterol efflux from cells to extracellular acceptors is governed by a number of known and even unknown pathways, and is influenced by the capacity and the quality of extracellular acceptor particles $(11,12,21)$. In the present study, human skin fibroblasts, obtained from a single normolipidemic donor, were used to assess the ability of plasma to promote cholesterol efflux. These cells abundantly express ABCA1 (20), and probably also ABCG1 (31), but contain negligible SR-BI (21). Thus, it is most likely that several pathways including ABCA1mediated cholesterol transport contribute to fibroblast cholesterol efflux, although their relative contribution is still unknown. It is well established that pre- $\beta$-HDL act as primary acceptors of cellular cholesterol via ABCA1 $(10,12,15,16)$, and the relevance of this pathway is emphasized by the observation that efflux from fibroblasts that lack functional ABCA1 is strongly diminished $(22,30)$. In our study, cholesterol efflux was positively related to pre- $\beta$-HDL formation and PLTP activity in multiple linear regression analysis, in agreement with the proposed important role of ABCA1-pre- $\beta$-HDL interaction to promote cholesterol efflux $(10,12,14)$, as well as with previous data showing that PLTP is able to stimulate cholesterol efflux directly via ABCA1 (32). It has been suggested that $A B C A 1$ and ABCG1 act in a coordinate fashion in cellular cholesterol removal by first promoting cholesterol efflux to pre- $\beta$-HDL and subsequently to more mature $\alpha$-HDL (14). LCAT activity may induce net cholesterol efflux via a non-specific cholesterol exchange mechanism (33). Very recently, it has been demonstrated that the presence of LCAT and apo E on $\alpha$-HDL particles is important for cholesterol efflux out of macrophages (34). In our study, cholesterol efflux from fibroblasts was independently related both to plasma EST and to apo E.

Clearly, the absence of a defect in the ability of plasma from MetS subjects to promote cellular cholesterol

Table 3 Plasma pre- $\beta$-high-density lipoprotein (HDL; formation), phospholipid transfer protein (PLTP) activity, cholesterol esterification (EST), cholesteryl ester transfer (CET), and cholesterol efflux from cultured fibroblasts to plasma according to metabolic syndrome and diabetes status.

\begin{tabular}{|c|c|c|c|c|c|}
\hline & $\begin{array}{l}\text { MetS-DM - } \\
(n=68)\end{array}$ & $\begin{array}{l}\text { MetS + DM - } \\
(n=21)\end{array}$ & $\begin{array}{l}\text { MetS-DM }+ \\
(n=26)\end{array}$ & $\begin{array}{l}\text { MetS + DM + } \\
(n=55)\end{array}$ & $P$ value \\
\hline Pre- $\beta$-HDL (apo A-I, g/l) & $0.051 \pm 0.019$ & $0.050 \pm 0.017$ & $0.054 \pm 0.023$ & $0.052 \pm 0.020$ & 0.79 \\
\hline Pre- $\beta$-HDL formation (apo A-I, g/l) & $0.317 \pm 0.068$ & $0.298 \pm 0.070$ & $0.299 \pm 0.069$ & $0.295 \pm 0.063$ & 0.27 \\
\hline PLTP activity (AU) & $93 \pm 10$ & $98 \pm 10$ & $97 \pm 10$ & $107 \pm 11^{\star \dagger, \ddagger}$ & $<0.001$ \\
\hline EST $(\mathrm{nmol} / \mathrm{ml}$ per $\mathrm{h}$ ) & $55.0 \pm 16.0$ & $60.8 \pm 12.8$ & $52.3 \pm 14.7$ & $69.1 \pm 18.0^{\star \dagger, \ddagger}$ & $<0.001$ \\
\hline CET $(\mathrm{nmol} / \mathrm{ml}$ per $\mathrm{h})$ & $19.8 \pm 7.4$ & $23.1 \pm 5.9^{*}$ & $19.2 \pm 6.1$ & $26.2 \pm 8.9^{\star \ddagger}$ & $<0.001$ \\
\hline Cholesterol efflux (\%/4 h) & $8.5 \pm 0.9$ & $8.6 \pm 1.1$ & $8.3 \pm 0.8$ & $8.8 \pm 0.9^{\ddagger}$ & 0.048 \\
\hline
\end{tabular}

Subjects are categorized into four groups: no metabolic syndrome and no diabetes (MetS $-\mathrm{DM}-$ ), metabolic syndrome without diabetes (MetS + DM -), diabetes without metabolic syndrome (MetS-DM+), and metabolic syndrome and diabetes (MetS $+\mathrm{DM}+)$. Data are shown as mean \pm s.D. $P$ values by ANOVA are shown: ${ }^{\star} P<0.05$ versus MetS $-\mathrm{DM}-;{ }^{\dagger} P<0.05$ versus MetS $+\mathrm{DM}-;{ }^{\ddagger} P<0.05$ versus MetS $-\mathrm{DM}+$. 
Table 4 Linear regression analysis of cellular cholesterol efflux with high-density lipoprotein (HDL) cholesterol, plasma apo A-I, pre- $\beta$-HDL (formation), phospholipid transfer protein (PLTP) activity, plasma cholesterol esterification (EST), cholesteryl ester transfer (CET), and plasma adiponectin in subjects with and without metabolic syndrome.

\begin{tabular}{llll}
\hline & $\begin{array}{l}\text { Metabolic syndrome absent } \\
(n=94)\end{array}$ & $\begin{array}{l}\text { Metabolic syndrome present } \\
(n=76)\end{array}$ & $\begin{array}{l}\text { Combined subjects } \\
(n=170)\end{array}$ \\
\hline HDL cholesterol & -0.03 & 0.02 & -0.08 \\
Apo A-I & 0.12 & 0.13 & 0.07 \\
Apo E & $0.35^{\ddagger}$ & $0.27^{\star}$ & $0.33^{\ddagger}$ \\
Pre- $\beta$-HDL & 0.14 & $0.31^{\dagger}$ & $0.21^{\dagger}$ \\
Pre- $\beta$-HDL formation & $0.38^{\ddagger}$ & $0.33^{\dagger}$ & $0.33^{\ddagger}$ \\
PLTP activity & $0.24^{\star}$ & $0.35^{\dagger}$ & $0.33^{\ddagger}$ \\
EST & $0.37^{\ddagger}$ & $0.39^{\ddagger}$ & $0.40^{\ddagger}$ \\
CET & $0.37^{\ddagger}$ & $0.28^{\star}$ & $0.35^{\ddagger}$ \\
Ln adiponectin & $0.02^{*}-0.07$ & -0.06 \\
\hline
\end{tabular}

Pearson correlation coefficients are shown: ${ }^{*} P<0.05 ;{ }^{\dagger} P<0.01 ;{ }^{\ddagger} P<0.001$.

removal is complementary to another report showing that the cellular cholesterol removal capacity of fibroblasts from individual MetS subjects is not impaired (22), and to the unchanged cholesterol efflux capacity out of SR-BIexpressing Fu 5AH cells observed in hypertriglyceridemia and insulin resistance $(24,25)$. Obviously, it will be important to replicate these findings using cholesterolloaded macrophage cell lines, such as THP1 or J774. It is generally appreciated that cellular cholesterol removal should be regarded as an anti-atherogenic process (8-10). Thus, the previous and present findings would suggest that the increased cardiovascular risk in MetS subjects $(6,7)$ is unlikely to be attributable to abnormalities in the early steps in the RCT pathway. This hypothesis needs to be tested in prospective studies.

Plasma PLTP activity was increased in MetS subjects after controlling for age, sex, and diabetes status, and this higher PLTP activity coincided with higher triglycerides, larger waist circumference, and insulin resistance in the present study. Such a higher PLTP activity agrees with previous reports from several research groups, in which a positive relationship of PLTP activity with hypertriglyceridemia, insulin resistance, and obesity with PLTP activity was observed (20, $35,36)$. In marked contrast, plasma PLTP activity was observed to be strongly decreased in one study comprising of a small cohort of non-diabetic MetS subjects, albeit in that study plasma PLTP activity was also very low in lean healthy subjects (18). We also documented increased plasma EST and CET in the whole group of MetS subjects. Plasma EST and subsequent CET are considered to be integrated processes (37). These abnormalities are, therefore, most likely explained at least in part by higher plasma triglycerides in MetS, reflecting increased very lowdensity lipoproteins that are able to accept cholesteryl esters from HDLs (17).

We assayed pre- $\beta$-HDL concentrations by crossed immunoelectrophoresis. The presently reported values in subjects without MetS or diabetes, being $0.051 \mathrm{~g}$ apo A-I/l on average, are similar to those in several other publications using a variety of assay methods, e.g., quantitative electrophoretic transfer followed by solidphase RIA (38), crossed immunoelectrophoresis (39), immunoblotting with chemiluminescent detection (40), non-denaturing two-dimensional gradient gel electrophoresis (41), and filtration and isotope dilution (42). In the healthy subjects, substantially higher pre- $\beta$ HDL concentrations have also been reported $(24,43-$ $45)$. These discrepancies could be due to differences in assay methodology and to different treatment of plasma samples during and after blood collection and plasma isolation, since pre- $\beta$-HDL may be formed in vitro.

In the present study, pre- $\beta$-HDL and pre- $\beta$-HDL formation were found to be unchanged in MetS. We therefore propose that increased activities of plasma lipid transfer proteins contribute to the maintenance of plasma pre- $\beta$-HDL concentration and formation in MetS, in spite of lower total plasma apo A-I and HDL cholesterol levels. The positive relationships of cellular cholesterol efflux with plasma PLTP activity, EST, and CET shown here may be interpreted to reflect potentially anti-atherogenic mechanisms. Accordingly, an inverse correlation of pre- $\beta$-HDL with intima media thickness, an established marker of subclinical atherosclerosis, was found recently (43). Nonetheless, the net effect of PLTP $(46,47)$ and CETP action may be pro-atherogenic $(48$, 49), much depending on metabolic circumstances like elevated plasma triglycerides (50).

In conclusion, this study demonstrates that cholesterol efflux out of fibroblasts to plasma from the MetS subjects is not defective, despite low HDL

Table 5 Independent relationships of cellular cholesterol efflux to plasma with high-density lipoprotein (HDL)-associated variables by multiple linear regression analysis (combined subjects, $n=170$ ).

\begin{tabular}{lcr}
\hline & $\boldsymbol{\beta}$ & $\boldsymbol{P}$ value \\
\hline Pre- $\beta$-HDL formation & 0.234 & 0.001 \\
EST & 0.226 & 0.005 \\
PLTP activity & 0.166 & 0.024 \\
Apo E & 0.153 & 0.047 \\
\hline
\end{tabular}

$\beta$, standardized regression coefficient; PLTP, phospholipid transfer protein; EST, cholesterol esterification. 
cholesterol. An increase in plasma EST, CET, and PLTP activity are responsible for part of the abnormalities associated with the MetS, and could modulate cardiovascular risk.

\section{Acknowledgements}

This study was supported by a grant from the Dutch Diabetes Research Foundation (grant no. 2001.00.012). Dr L D Dikkeschei, PhD (Laboratory of Clinical Chemistry, Isala Clinics, Zwolle, the Netherlands) performed the lipid and apolipoprotein assays. A Zonneveld and L van Varkvan der Zee (Laboratory for Vascular Medicine, Erasmus University Medical Center, Rotterdam) and M J A van Wijland (Department of Experimental Hepatology, Academic Medical Center, Amsterdam, the Netherlands) carried out the PLTP activity measurements and cellular cholesterol efflux studies respectively. F Perton, PhD (Laboratory Center, University Medical Center, Groningen, the Netherlands) is acknowledged for the assay of pre- $\beta$-HDL, cholesterol esterification, and cholesteryl ester transfer.

\section{References}

1 Kahn R, Buse J, Ferrannini E \& Stern M. The metabolic syndrome: time for a critical appraisal: joint statement from the American Diabetes Association and the European Association for the Study of Diabetes. Diabetes Care 200528 2289-2304.

2 World Health Organisation. Expert Committee on diabetes mellitus: definition, diagnosis, and classification of Diabetes Mellitus and its complications. Report WHO 1999.

3 Executive Summary of The Third Report of The National Cholesterol Education Program (NCEP). Expert panel on detection, evaluation, and treatment of high blood cholesterol in adults (Adult Treatment Panel III). Journal of the American Medical Association 2001285 2486-2497.

4 Grundy SM, Brewer HB Jr, Cleeman JI, Smith SC Jr \& Lenfant C. Definition of metabolic syndrome: Report of the National Heart, Lung, and Blood Institute/American Heart Association conference on scientific issues related to definition. Circulation 2004109 433-438.

5 Alberti KG, Zimmet P \& Shaw J. The metabolic syndrome - a new worldwide definition. Lancet 2005366 1059-1062.

6 Ford ES. Risks for all-cause mortality, cardiovascular disease, and diabetes associated with the metabolic syndrome: a summary of the evidence. Diabetes Care 200528 1769-1778.

7 Qiao Q \& the Decode study group, Comparison of different definitions of the metabolic syndrome in relation to cardiovascular mortality in European men and women. Diabetologia $2006 \mathbf{4 9}$ 2837-2846.

8 Fielding CJ \& Fielding PE. Molecular physiology of reverse cholesterol transport. Journal of Lipid Research 199536 211-228.

9 Tall AR. An overview of reverse cholesterol transport. European Heart Journal 199819 A31-A35.

10 Von Eckardstein A, Nofer JR \& Assmann G. High density lipoproteins and arteriosclerosis. Role of cholesterol efflux and reverse cholesterol transport. Arteriosclerosis, Thrombosis, and Vascular Biology 200121 13-27.

11 Rothblat GH, Llera-Moya M, Atger V, Kellner-Weibel G, Williams DL \& Phillips MC. Cell cholesterol efflux: integration of old and new observations provides new insights. Journal of Lipid Research 199940 781-796.
12 Yancey PG, Bortnick AE, Kellner-Weibel G, De la Llera-Moya M, Phillips MC \& Rothblat GH. Importance of different pathways of cellular cholesterol efflux. Arteriosclerosis, Thrombosis, and Vascular Biology 200323 712-719.

13 Wang N, Lan D, Chen W, Matsuura F \& Tall AR. ATP-binding cassette transporters G1 and G4 mediate cellular cholesterol efflux to high-density lipoproteins. PNAS 2004101 9774-9779.

14 Gelissen IC, Harris M, Rye KA, Quinn C, Brown AJ, Kockx M, Cartland S, Packianathan M, Kritharides L \& Jessup W. ABCA1 and ABCG1 synergize to mediate cholesterol export to apoA-I. Arteriosclerosis, Thrombosis, and Vascular Biology 200626 534-540.

15 Favari E, Lee M, Calabresi L, Franceschini G, Zimetti F, Bernini F \& Kovanen PT. Depletion of pre-beta-high density lipoprotein by human chymase impairs ATP-binding cassette transporter A1but not scavenger receptor class B type I-mediated lipid efflux to high density lipoprotein. Journal of Biological Chemistry 2004279 9930-9936.

16 Rye KA \& Barter PJ. Formation and metabolism of prebetamigrating, lipid-poor apolipoprotein A-I. Arteriosclerosis, Thrombosis, and Vascular Biology 200424 421-428.

17 Borggreve SE, De Vries R \& Dullaart RPF. Alterations in highdensity lipoprotein metabolism and reverse cholesterol transport in insulin resistance and type 2 diabetes mellitus: role of lipolytic enzymes, lecithin:cholesterol acyltransferase and lipid transfer proteins. European Journal of Clinical Investigation 200333 1051-1069.

18 Ji J, Watts GF, Johnson AG, Chan DC, Ooi EM, Rye KA, Serone AP \& Barrett PH. High-density lipoprotein (HDL) transport in the metabolic syndrome: application of a new model for HDL particle kinetics. Journal of Clinical Endocrinology and Metabolism 200691 973-979.

19 Verges B, Petit JM, Duvillard L, Dautin G, Florentin E, Galland F \& Gambert P. Adiponectin is an important determinant of apoA-I catabolism. Arteriosclerosis, Thrombosis, and Vascular Biology 2006 26 1364-1369.

20 de Vries R, Kerstens MN, Sluiter WJ, Groen AK, van Tol A \& Dullaart RPF. Cellular cholesterol efflux to plasma from moderately hypercholesterolaemic type 1 diabetic patients is enhanced, and is unaffected by simvastatin treatment. Diabetologia $2005 \mathbf{4 8}$ 1105-1113.

21 Duong M, Collins HL, Jin W, Zanotti I, Favari E \& Rothblat GH. Relative contributions of ABCA1 and SR-BI to cholesterol efflux to serum from fibroblasts and macrophages. Arteriosclerosis, Thrombosis, and Vascular Biology 200626 541-547.

22 Alenezi MY, Marcil M, Blank D, Sherman M \& Genest J Jr. Is the decreased high-density lipoprotein cholesterol in the metabolic syndrome due to cellular lipid efflux defect? Journal of Clinical Endocrinology and Metabolism 200489 761-764.

23 Kiss RS, Kavaslar N, Okuhira K, Freeman MW, Walter S, Milne RW, McPherson R \& Marcel YL. Genetic etiology of isolated low HDL syndrome: incidence and heterogeneity of efflux defects. Arteriosclerosis, Thrombosis, and Vascular Biology 200727 1139-1145.

24 Fournier N, Francone O, Rothblat G, Goudouneche D, Cambillau M, Kellner-Weibel G, Robinet P, Royer L, Moatti N, Simon A \& Paul JL. Enhanced efflux of cholesterol from ABCA1expressing macrophages to serum from type IV hypertriglyceridemic subjects. Atherosclerosis $2003171287-293$.

25 Dullaart RPF \& van Tol A. Role of phospholipid transfer protein and prebeta-high density lipoproteins in maintaining cholesterol efflux from Fu5AH cells to plasma from insulin-resistant subjects. Scandinavian Journal of Clinical and Laboratory Investigation 2001 $6169-74$.

26 Matthews DR, Hosker JP, Rudenski AS, Naylor BA, Treacher DF \& Turner RC. Homeostasis model assessment: insulin resistance and beta-cell function from fasting plasma glucose and insulin concentrations in man. Diabetologia $1985 \mathbf{2 8} 412-419$.

27 Van Haperen R, van Tol A, Venmeulen P, Jauhiainen M, van Gent T, Van den Berg P, Ehnholm S, Grosveld F, Van der Kamp A \& De Crom R. Human plasma phospholipid transfer protein 
increases the antiatherogenic potential of high density lipoproteins in transgenic mice. Arteriosclerosis, Thrombosis, and Vascular Biology $2000201082-1088$.

28 Speijer H, Groener JEM, van Ramshorst E \& van Tol A. Different locations of cholesteryl ester transfer protein and phospholipid transfer protein activities in plasma. Atherosclerosis 199190 159-168.

29 Dullaart RPF, Riemens SC, Scheek LM \& van Tol A. Insulin decreases plasma cholesteryl ester transfer but not cholesterol esterification in healthy subjects as well as in normotriglyceridaemic patients with type 2 diabetes. European Journal of Clinical Investigation $199929663-671$.

30 Hovingh GK, van Wijland MJ, Brownlie A, Bisoendial RJ, Hayden MR, Kastelein JJ \& Groen AK. The role of the ABCA1 transporter and cholesterol efflux in familial hypoalphalipoproteinemia. Journal of Lipid Research $2003 \mathbf{4 4} 1251-1255$.

31 Boadu E, Choi HY, Lee DW, Waddington EI, Chan T, Asztalos B, Vance JE, Chan A, Castro G \& Francis GA. Correction of apolipoprotein A-I-mediated lipid efflux and high density lipoprotein particle formation in human Niemann-Pick type C disease fibroblasts. Journal of Biological Chemistry $2006 \mathbf{2 8 1}$ 37081-37090.

32 Oram JF, Wolfbauer G, Vaughan AM, Tang C \& Albers JJ. Phospholipid transfer protein interacts with and stabilizes ATP-binding cassette transporter A1 and enhances cholesterol efflux from cells. Journal of Biological Chemistry $2003 \mathbf{2 7 8}$ 52379-52385.

33 Czarnecka H \& Yokoyama S. Regulation of cellular cholesterol efflux by lecithin: cholesterol acyltransferase reaction through nonspecific lipid exchange. Journal of Biological Chemistry 1996 $2712023-2028$.

34 Matsuura F, Wang N, Chen W, Jiang XC \& Tall AR. HDL from CETP-deficient subjects shows enhanced ability to promote cholesterol efflux from macrophages in an apoE- and ABCG1dependent pathway. Journal of Clinical Investigation $2006 \mathbf{1 1 6}$ 1435-1442.

35 Kaser S, Sandhofer A, Föger B, Ebenbichler CF, Igelseder B, Malaimare L, Paulweber B \& Patsch JR. Influence of obesity and insulin sensitivity on phospholipid transfer protein activity. Diabetologia $2001 \mathbf{4 4} 1111-1117$.

36 Jonkers IJ, Smelt AH, Hattori H, Scheek LM, van Gent T, De Man FH, Van der Laarse A \& van Tol A. Decreased PLTP mass but elevated PLTP activity linked to insulin resistance in HTG: effects of bezafibrate therapy. Journal of Lipid Research $2003 \mathbf{4 4} 1462-1469$.

37 Fielding CJ \& Fielding PE. Regulation of human plasma lecithin:cholesterol acyltransferase activity by lipoprotein acceptor cholesteryl ester content. Journal of Biological Chemistry 1981256 2102-2104.

38 Ishida BY, Frolich J \& Fielding CJ. Prebeta-migrating high density lipoprotein: quantitation in normal and hyperlipidemic plasma by solid phase radioimmunoassay following electrophoretic transfer. Journal of Lipid Research $1987 \mathbf{2 8}$ 778-786.

39 Neary R, Bhatnagar D, Durrington P, Ishola M, Arrol S \& Mackness M. An investigation of the role of lecithin:cholesterol acyltransferase and triglyceride-rich lipoproteins in the metabolism of pre-beta high density lipoproteins. Atherosclerosis 1991 89 35-48.
40 O'Kane MJ, Wisdom GB, McEneny J, McFerran NV \& Trimble ER. Pre-beta high-density lipoprotein determined by immunoblotting with chemiluminescent detection. Clinical Chemistry 199238 2273-2277.

41 Miida T, Nakamura Y, Inano K, Matsuto T, Yamaguchi T, Tsuda T \& Okada M. Pre $\beta_{1}$-high-density lipoprotein increases in coronary artery disease. Clinical Chemistry 199642 1992-1995.

42 O'Connor PM, Zysow BR, Schoenhaus SA, Ishida BY, Kunitake ST, Naya-Vigne JM, Duchateau PN, Redberg RF, Spencer SJ, Mark S, Mazur M, Heilbron DC, Jaffe RB, Malloy MJ \& Kane JP. Prebeta-1 HDL in plasma of normolipidemic individuals: influences of plasma lipoproteins, age, and gender. Journal of Lipid Research 199839 670-678.

43 Watanabe H, Soderlund S, Soro-Paavonen A, Hiukka A, Leinonen E, Alagona C, Salonen R, Tuomainen TP, Ehnholm C, Jauhiainen M \& Taskinen MR. Decreased high-density lipoprotein (HDL) particle size, prebeta-, and large HDL subspecies concentration in Finnish low-HDL families: relationship with intimamedia thickness. Arteriosclerosis, Thrombosis, and Vascular Biology 200626 897-902.

44 Chetiveaux M, Ouguerram K, Zair Y, Maugere P, Falconi I, Nazih H \& Krempf M. New model for kinetic studies of HDL metabolism in humans. European Journal of Clinical Investigation $20043 \mathbf{4}$ 262-267.

45 Asztalos BF, Horvath KV, Kajinami K, Nartsupha C, Cox CE, Batista M, Schaefer EJ, Inazu A \& Mabuchi H. Apolipoprotein composition of HDL in cholesteryl ester transfer protein deficiency. Journal of Lipid Research $2004 \mathbf{4 5} 448-455$.

46 de Vries R, Dallinga-Thie GM, Smit AJ, Wolffenbuttel BHR, van Tol A \& Dullaart RPF. Elevated plasma phospholipid transfer protein activity is a determinant of carotid intima-media thickness in type 2 diabetes mellitus. Diabetologia $200649398-404$.

47 Schlitt A, Bickel C, Thumma P, Blankenberg S, Rupprecht HJ, Meyer J \& Jiang XC. High plasma phospholipid transfer protein levels as a risk factor for coronary artery disease. Arteriosclerosis, Thrombosis, and Vascular Biology 200323 1857-1862.

48 de Vries R, Perton FG, Dallinga-Thie GM, van Roon AM, Wolffenbuttel BHR, van Tol A \& Dullaart RPF. Plasma cholesteryl ester transfer is a determinant of intima-media thickness in type 2 diabetic and nondiabetic subjects: role of CETP and triglycerides. Diabetes $2005 \mathbf{5 4} 3554-3559$.

49 Boekholdt SM, Kuivenhoven JA, Wareham NJ, Peters RJ, Jukema JW, Luben R, Bingham SA, Day NE, Kastelein JJ \& Khaw KT. Plasma levels of cholesteryl ester transfer protein and the risk of future coronary artery disease in apparently healthy men and women: the prospective EPIC (European Prospective Investigation into Cancer and nutrition)-Norfolk population study. Circulation $20041101418-1423$.

50 Dullaart RP, Dallinga-Thie GM, Wolffenbuttel BH \& van Tol A. CETP inhibition in cardiovascular risk management: a critical appraisal. European Journal of Clinical Investigation 200737 90-98.

Received 10 September 2007

Accepted 16 October 2007 